\title{
Simulation Calculation of Air Conditioning System Under Complex Vehicle Conditions
}

\author{
He Chang ${ }^{1, *}$, Lili Cheng ${ }^{1}$ \\ ${ }^{1}$ Applied Technology College, Jilin University, Chang Chun, 130000, China
}

\begin{abstract}
Based on the Simulink the vehicle air conditioning simulation platform for the whole vehicle is established. The multi model joint simulation system can predict the performance parameters and energy consumption of the air conditioning system under the conditions of different vehicle speed, temperature and humidity. It can coordinate the simulation of the temperature change process inside the passenger compartment with the performance of the air conditioning system.
\end{abstract}

\section{Introduction}

Air conditioning system is one of the most significant system as accessory that influents the factors of fuel consumption in traditional automobile. Similar research data show that air conditioning fuel consumption accounts for $5 \%$ of the total vehicle fuel consumption. Length of its working time on air conditioning system of electric vehicle. It is that directly affects the battery power of electric vehicles, and indirectly affects the mileage of electric vehicles.

Therefore, it is necessary to study and predict the performance and energy consumption of air conditioning system by advanced numerical calculation method. The operation of the vehicle air conditioning system is a dynamic process. Based on simulation method it is predicted air conditioning system performance and energy consumption under complex conditions which are the dynamic process of the vehicle, passenger compartment temperature and the external environment temperature.

\section{Model and parameter}

In this paper it is established the air conditioning system performance model, passenger compartment comfort model and vehicle driving model that it forms a joint simulation platform. Based on the Simulink platform, it is carried out the coupling calculation of each model through the means of data transmission.

\subsection{Vehicle driving model}

The vehicle running state model is mainly used to express the important characteristics of vehicle running process. The basic input parameters include: vehicle speed, engine speed, gear train speed ratio, slope, vehicle running time, etc. The speed is expressed by the speed time curve of the vehicle. As shown in the figure1.

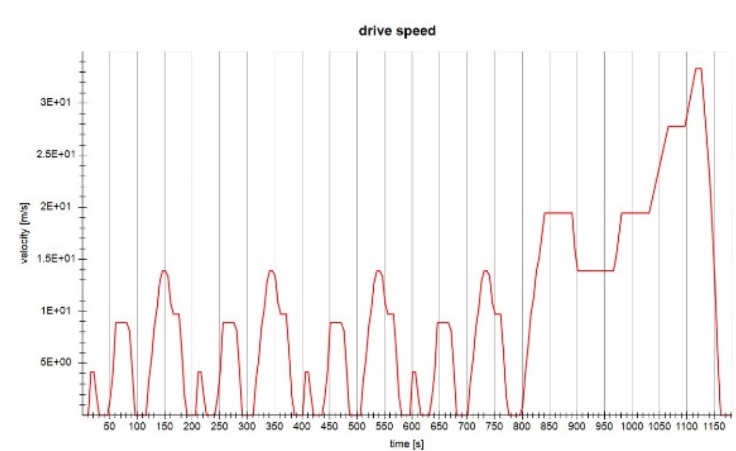

Fig. 1. drive speed curve

\subsection{Vehicle environment}

The vehicle environmental is mainly used to express the direct factors that affect the vehicle and air conditioning system in the process of vehicle operation. The main input parameters include: ambient temperature, ambient humidity and radiation intensity. As shown in the Table1.

Table 1. Basic parameters of vehicle operation.

\begin{tabular}{|c|c|c|c|}
\hline Element & Name & Parameter & Unit \\
\hline 1 & speed & curve & - \\
\hline 2 & temperature & 37 & ${ }^{\circ} \mathrm{C}$ \\
\hline 3 & humidity & 50 & $\%$ \\
\hline 4 & radiation & 850 & $\mathrm{w} / \mathrm{m} 2$ \\
\hline 5 & speed ratio & 1.4 & - \\
\hline
\end{tabular}

\subsection{Air conditioning model}

Air conditioning model is a system composed of complex components. The air conditioning model

\footnotetext{
* Corresponding author: changhe@jlu.edu.cn
} 
mainly includes: compressor, condenser, evaporator, expansion valve, high pressure pipe, low pressure pipe and other accessories. As shown in the Table2.

Table 2. Parameters of air conditioning.

\begin{tabular}{|c|c|c|c|}
\hline Element & Name & Parameter & Unit \\
\hline 1 & $\begin{array}{c}\text { Heat of } \\
\text { condenser }\end{array}$ & 13 & $\mathrm{~kW}$ \\
\hline 2 & $\begin{array}{c}\text { Heat of } \\
\text { evaporator }\end{array}$ & 4.5 & $\mathrm{~kW}$ \\
\hline 3 & $\begin{array}{c}\text { Compressor } \\
\text { displacemen } \\
\mathrm{t}\end{array}$ & 85 & $\mathrm{~cm} 3$ \\
\hline 4 & $\begin{array}{c}\text { Compressor } \\
\text { speed }\end{array}$ & $0-3900$ & $1 / \mathrm{min}$ \\
\hline 5 & Refrigerant & $\mathrm{R} 134 \mathrm{~A}$ & - \\
\hline
\end{tabular}

\subsection{Passenger compartment comfort model}

To study the performance and energy consumption of air conditioning system, the heat load of vehicle environment cabin should be focused on. Therefore, it is very necessary to establish the vehicle occupant compartment model. The model includes: vehicle occupant compartment volume, body material properties, body glass area parameters, interior material properties, etc. As shown in the Table 3.

Table 3. parameters of passenger compartment.

\begin{tabular}{|c|c|c|c|}
\hline Element & Name & Parameter & Unit \\
\hline 1 & $\begin{array}{c}\text { Internal } \\
\text { volume }\end{array}$ & 3.7 & $\mathrm{~m} 3$ \\
\hline 2 & External area & 7 & $\mathrm{~m} 2$ \\
\hline 3 & Vehicle glass & 1.3 & $\mathrm{~m}$ \\
\hline 4 & $\begin{array}{c}\text { Incident } \\
\text { angle }\end{array}$ & 36 & $\circ$ \\
\hline 5 & $\begin{array}{c}\text { material } \\
\text { quality }\end{array}$ & 30 & $\mathrm{~kg}$ \\
\hline
\end{tabular}

\section{Multi model joint simulation}

The vehicle running model can simulate the driving state of the vehicle at different speeds according to the input speed curve. The air conditioning system model and the vehicle running model are coupled by the relationship between the engine speed and the air conditioning compressor speed ratio. When the vehicle is running, the compressor works with the engine speed, and the air conditioning system starts to run. The compressor compresses the condensing agent to the expansion valve, which is throttled by the expansion valve. After entering the evaporator, the refrigerant evaporates from liquid state to gas state in the evaporator to absorb heat, to realize the cooling inside the passenger compartment. Finally, the cooling capacity of the air conditioning system and the heat source in the vehicle can be balanced, and the performance evaluation and prediction of the air conditioning system can be realized. Generally, the initial temperature in the environment is $55^{\circ} \mathrm{C}$ under high temperature, so the initial temperature in the occupant compartment is set as $55^{\circ} \mathrm{C}$ in the simulation calculation of the passenger compartment. As shown in the figure 2 .

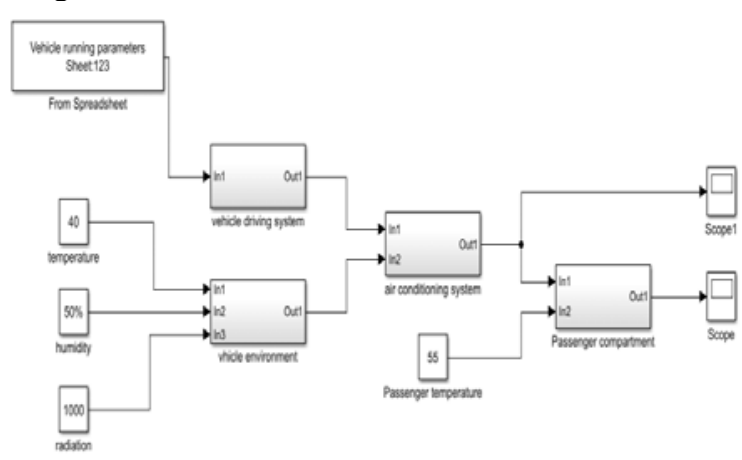

Fig. 2. Simulink simulation platform

\section{Results and performance analysis}

The simulation model is used to calculate the performance of each system part in the transient state of air conditioning system under complex conditions. When the vehicle is running, the temperature inside the car is $55{ }^{\circ} \mathrm{C}$, and the air conditioning system starts to work. The vehicle speed starts from standstill to $40 \mathrm{~km} / \mathrm{h}$ and goes through several cycles. At the same time, the air conditioning compression changes with the engine speed. In the first $800 \mathrm{~s}$, the change trend was basically the same. When it reaches 800 , the output power of the compressor is the minimum. After $800 \mathrm{~s}$, due to the increase of vehicle speed, the engine needs to input more torque, which leads to the increase of the speed of the air conditioning compressor, and the output power of the compressor also changes. As shown in the figure3.

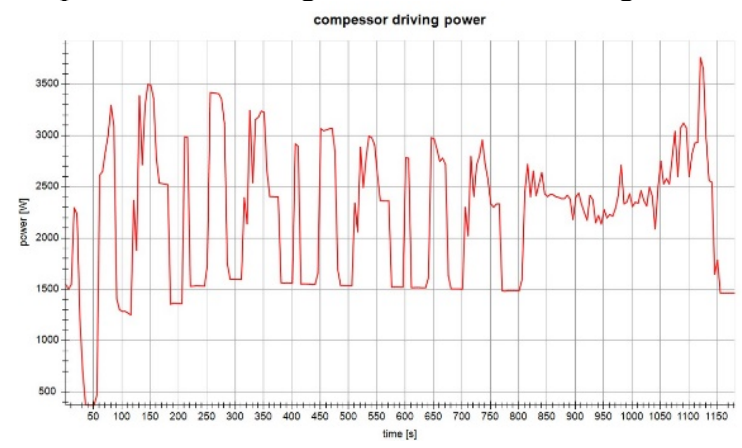

Fig.3. compressor driving power.

The vehicle speed starts from standstill to $40 \mathrm{~km} / \mathrm{h}$ and goes through several cycles. With the change of air conditioning compression speed, the change trend of air conditioning cooling power is consistent. In the first 800 s, the change trend was basically the same. When it reaches 800 , the refrigeration power of the compressor is the minimum. After $800 \mathrm{~s}$, because the air conditioner in the passenger compartment is still refrigeration, the cooling power of the compressor also changes. As shown in the figure4. 


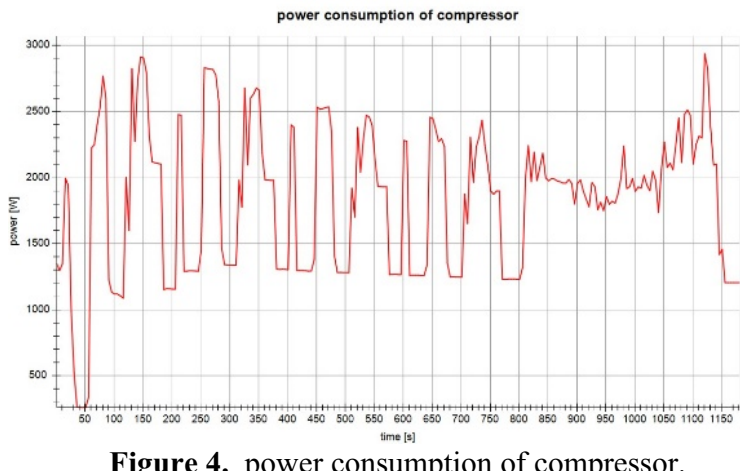

Figure 4. power consumption of compressor.

During the operation of the vehicle, the temperature inside the passenger compartment is the highest, and the air conditioner is turned on for full load cooling, so the cooling capacity of the evaporator is the largest in the initial stage. When the time is $600-800 \mathrm{~s}$, the refrigeration capacity of the evaporator basically keeps fluctuating in a certain range, and remains unchanged in 800-1100s. In the last 50 seconds, because of the decrease of vehicle speed, the compressor speed decreases, and the refrigerant flow decreases after entering the evaporator, resulting in the reduction of refrigeration capacity. As shown in the figure 5 .

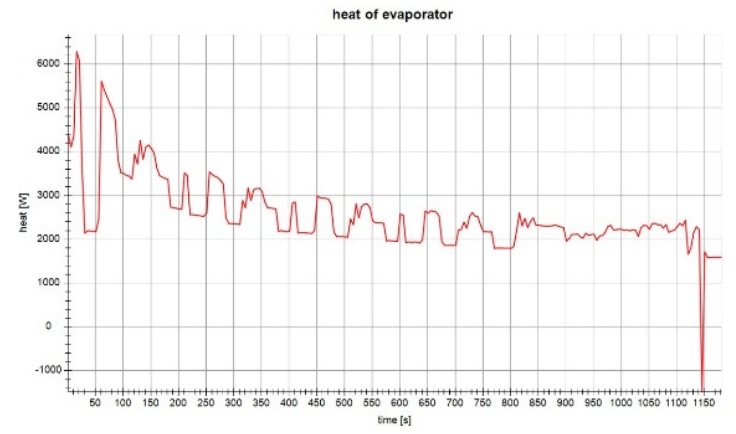

Fig. 5. heat of evaporator

The refrigerant flow in the expansion valve, when the time is between $000-600$ s, the refrigerating capacity of the evaporator gradually decreases, and remains unchanged in $800-1100 \mathrm{~s}$. In the last $50 \mathrm{~s}$, the compressor stops working due to the decrease of vehicle speed, resulting in the refrigeration capacity of 0 . As shown in the figure6.

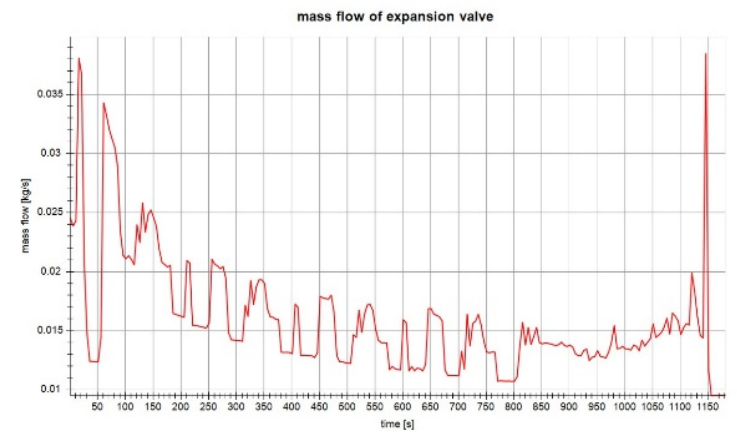

Fig. 6. mass flow of expansion valve

When the air conditioner is turned on for full load cooling, the system starts to cycle, and the cooling capacity of condenser also changes due to the change of cooling capacity demand. When the time is $600-800 \mathrm{~s}$, the heat dissipation capacity of the condenser is basically maintained in a certain range, and remains unchanged in $800-1100$ s. In the last $50 \mathrm{~s}$, the speed of the compressor decreases due to the decrease of vehicle speed, which leads to the decrease of cooling capacity and the heat dissipation of condenser is 0 . As shown in the figure 7 .

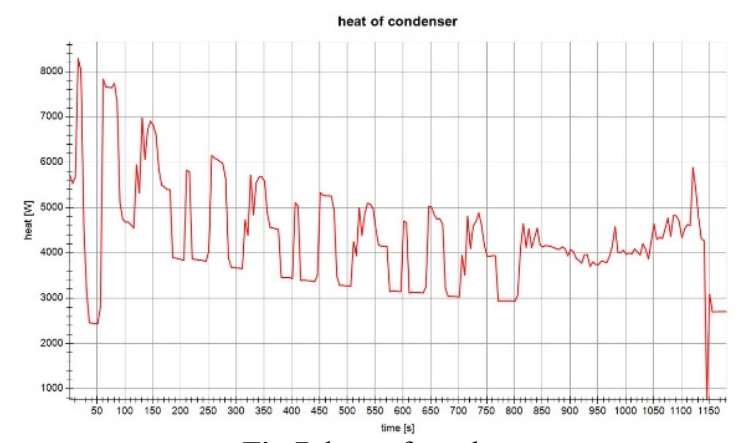

Fig.7. heat of condenser.

\section{Comfort analysis}

The temperature drop curve is used to evaluate the temperature and temperature rise of the cultural relics in the crew cabin, which is a comfort index of the member's comfort. The air temperature near the human trunk is usually used for evaluation. At the beginning of the simulation, the maximum internal temperature of the cabin is $45^{\circ} \mathrm{C}$ due to the environmental temperature and solar radiation. The air conditioning compressor starts, the system cycle starts to run, and the refrigerant begins to enter the evaporator, and evaporates inside the evaporator to absorb the heat of the air in the car. This process causes the temperature inside the occupant compartment to gradually decrease. The operation manager of the whole vehicle has been running for 1200 s. During this period, the temperature in the car has not reached the expected target, so the curve has been decreasing gradually until the simulation stops. As shown in the figure8.

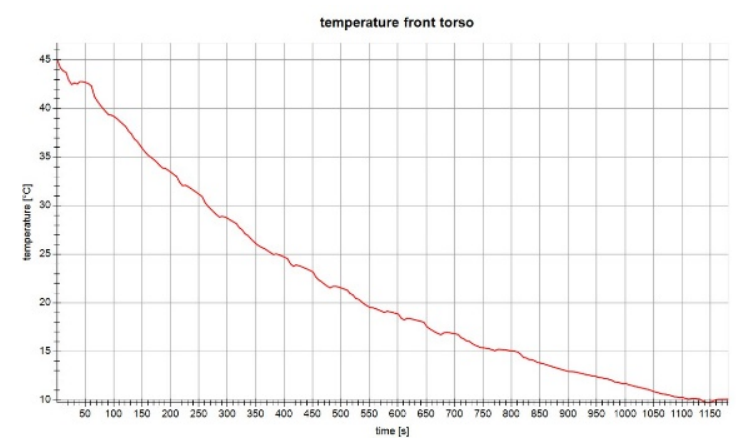

Fig.8. temperature front torso

\section{Conclusion}

1. Based on the Simulink platform, the air conditioning system model, passenger cabin comfort model and vehicle driving model of a certain vehicle are established respectively, and the coupling calculation of each model by means of data transmission is carried out, and the 
vehicle air conditioning simulation platform for the whole vehicle is established.

2.Through the comparison of simulation results and experimental data, the accuracy of the simulation model meets the requirements of engineering development accuracy. The multi model joint simulation system can predict the performance parameters and energy consumption of the air conditioning system under the conditions of different vehicle speed, temperature and humidity.

3. Multi model joint simulation can well simulate the cooling effect and energy consumption of air conditioning system during vehicle operation, and predict and analyze whether the performance of air conditioning system meets the design objectives. The advanced numerical simulation method can shorten the development cycle of air conditioning system and reduce the cost of product design.

\section{References}

1. GH Lee, JY Yoo. Performance analysis and simulation of automobile air conditioning system[J]. International Journal Refrigeration .2000,23(3):242 255

2. Han $T$, Chen $K$ H. Assessment of various environmental thermal loads on passenger compartment soak and cool-down analyses[C]. SAE Technical Paper 2009-01-1148, 2009.

3. Sen S, Selokar M. Numerical Simulation and Validation of Cabin Aiming and Cool-Down of a Passenger Car[J]. SAE International Journal of Passenger Cars-Mechanical Systems, 2016,9(201601-0251):52-6

4. Wang B, Liu S, Jin Y. Simulation and analysis of human thermal comfort[J]. International Journal of Man-Machine-Environment Systems Engineering, 2007, 1(1): 37-49.

5. FELIX R A. A Numerical Analysis on Aircooling Performance of Passen-ger Cars[C]// SAE Paper, 2010-01-0554.2 